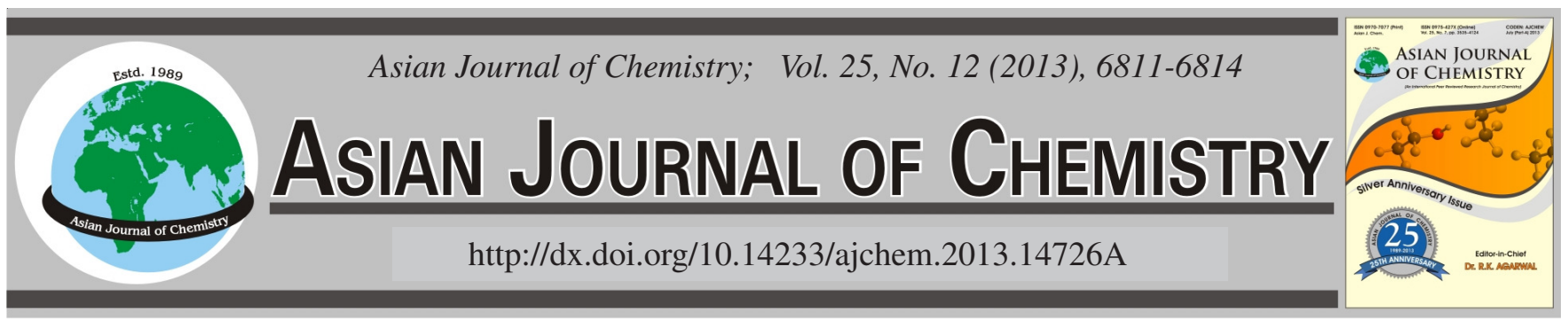

\title{
Adsorption and Purification of Zinc in Mining Wastewater Using Microbial Immobilization Technology
}

\author{
Shouwu WAnG ${ }^{1, *}$ and WenBin Chen $^{2}$
}

${ }^{1}$ Department of Chemical Engineering, Huaihai Institute of Technology, Lianyungang 222005, P.R. China

${ }^{2}$ School of Chemistry Engineering, Huaihai Institute of Technology, Liangyungang 222005, Jiangsu Province, P.R. China

*Corresponding author: Tel: +86 13861426858; E-mail: lygcwb11@163.com

(Received: 20 October 2012;

Accepted: 5 June 2013)

AJC-13577

The Leptospirillum ferrooxidans has been selected and cultivated from mine area and applied in treatment of $\mathrm{Zn}^{2+}$-containing wastewater |
in the laboratory and real $\mathrm{Zn}^{2+}$-containing wastewater. The principle of its adsorption process was probed. The results show that the main
factors which affect the $\mathrm{zinc}$ uptake are $\mathrm{pH}$ value, ways of pretreatment, contacting time, co-existing ions, Leptospirillum ferrooxidans
concentration in solutions, etc. It was able to adsorb $\mathrm{Zn}^{2+}$ efficiently. After adsorption steps of the treatment, the concentration of $\mathrm{Zn}^{2+}$ in |
solution met the standard for treating wastewater. After adsorption treatment of containing zinc mine wastewater, the concentration of |
zinc ions reaches the first class of irrigation water quality standards.
Key Words: Leptospirillum ferrooxidans, Mining wastewater, Zinc.

\section{INTRODUCTION}

Mineral resources are the necessary material basis for human civilization. In the process of development and utilization of minerals, the destruction and change of the environment are inevitable and producing a variety of contaminants at the same time, then contaminating air, water and soil and bringing many adverse effects to the ecological environment and human health. Meanwhile, the mineral resources is a nonrenewable natural resources, therefore, the environmental problems generated by mining development increasingly caught the attention from many countries. On the one hand we should protect the mine environment and prevent pollution; on the other hand, the rational exploitation and protection of mineral resources are needed.

A part of the heavy metal contaminated mine drainage water into the fields with the irrigation channels lost and some is absorbed by plants, most of the remaining accumulated in the soil, when the concentration of it reach a certain number, there will appear diseases of crops and cause great harm to human and aquatic life ${ }^{1}$.

Zinc is an important material which maintain normal body growth and metabolism, but if the zinc contents in human and animals is too high, there will have adverse effects, such as restrain the activity and sterilization capacity of phagocytosis, which will reduce the body's immune function, so that reduced resistance and increased susceptibility to diseases. Therefore, zinc wastewater treatment is still the world's major research topic in the field of environmental protection ${ }^{2}$. Zinc metal wastewater treatment methods are generally physical and chemical methods, such as the neutralization and precipitation method, coagulation and precipitation method, adsorption method, ion exchange method, membrane separation method, etc. $^{3,4}$. In recent years, biological methods have been a new task among scientists at home and abroad, it has the advantages of high efficiency, selectivity, big adsorption capacity and without secondary pollution and the cost of treating wastewater is low ${ }^{5}$.

In past 30 years, the international research of microbial biodiversity, community composition, physiological and biochemical characteristics typical of micro-organisms, industrial application of microbial isolation, culture and other areas in acid mine drainage have increased significantly. Studies have shown that, Prokaryotic microorganisms in acid mine drainage are mainly true bacteria and $\operatorname{archaea}^{6}$, there has 11 categories of bacteria and archaea were detected. So far, the most studied are two types of iron-oxidizing bacteria i.e., Acidothiobacillus ferrooxidans and Leptospirillum.

In general, in areas contaminated by heavy metals can selecte the antimicrobial, these resistant organisms have a potential heavy metal adsorption and they are a great source of heavy metals adsorbent and precipitant. Since 1995, the research of using biological absorbent to treat heavy metal wastewater at home and abroad emerged a growth trend year 
by year and the growth rate is also increasing annually. It is suggested that biosorbent has become the focus and emphasis of researching and applying metal pollution in water and it has broad prospects. In this paper, we studied using sodium alginate to fasten the iron-oxidizing bacterium Leptospirillum ferrooxidans which were selected from the acid mine drainage and then adsorbed the zinc in mine, through conditional experiments and orthogonal tests obtained the optimum adsorption conditions for zinc and the effect on zinc adsorption caused by each single-factor, conduct purification research on the mine wastewater contaminated by heavy metals.

\section{EXPERIMENTAL}

WFJ-7200 Spectrophotometer (Unico (Shanghai) Instruments Co., Ltd.); pHSJ-5-type laboratory pH meter (Shanghai Instrument Co., Ltd. established); SHP-180 Biochemical Incubator (Shanghai Lei magnetic Instrument Factory); calcium chloride solution: $20 \mathrm{mg} / \mathrm{L}$.

Preparation of Leptospirillum ferrooxidans ball cells: Preparation of $2 \%$ (mass volume concentration) of Leptospirillum ferrooxidans cell mixture; draw a syringe of Leptospirillum ferrooxidans cell mixture, gradually adding into the $\mathrm{CaCl}_{2}$ solution, aging $4 \mathrm{~h}$; dump the $\mathrm{CaCl}_{2}$ solution, wash Leptospirillum ferrooxidans cells with distilled water at least 3 times.

Experimental methods: In the experiment, we use the mine wastewater in a tungsten mine in Hunan as the treatment samples; the initial concentration of zinc in the mine wastewater samples is $3.89 \mathrm{mg} / \mathrm{L}$.

Determination methods of zinc: In the weak acid $(\mathrm{pH}$ 3.5-4.0) conditions, zinc and ammonium pyrrolidine dithiocarbamate (APDC) and sodium diethyl dithiocarbamate (DDTC-Na) form a chelate, by the extraction and separation of methyl isobutyl ketone (MIBK), in the organic phase, zinc is atomized in the acetylene-air flame. Determine the atomic absorbance at the characteristic absorption wavelength.

Temperature, small ball concentration, $\mathrm{pH}$, time orthogonal experiments block: In the design of this experiment, there are four factors: temperature, the concentration of small ball, pH, time, they were set to A, B, C, D, each element have 4 levels, use the 4 levels with 4 factors divide the orthogonal chart into 16 groups to which $\mathrm{A} 1: 37^{\circ} \mathrm{C}, \mathrm{A} 2: 30^{\circ} \mathrm{C}$, A3: $20^{\circ} \mathrm{C}, \mathrm{A} 4: 10^{\circ} \mathrm{C}$; B1: $0.9 \mathrm{~g} / \mathrm{L}, \mathrm{B} 2: 1.0 \mathrm{~g} / \mathrm{L}, \mathrm{B} 3: 1.1 \mathrm{~g} / \mathrm{L}$, B4: $1.2 \mathrm{~g} / \mathrm{L} ; \mathrm{C} 1: \mathrm{pH}=4, \mathrm{C} 2: \mathrm{pH}=5, \mathrm{C} 3: \mathrm{pH}=6, \mathrm{C} 4: \mathrm{pH}=7$; D1: 90 min, D2: 100 min, D3: 110 min, D4: 120 min.

Test steps: Take wastewater containing zinc, add sodium alginate immobilized adsorbent Leptospirillum ferrooxidans ball, put it into the shaker in factor A above in the different temperature, shake the factor D in different times, until the end of shaking time, filtering, measuring the heavy metal zinc values in zinc wastewater.

\section{RESULTS AND DISCUSSION}

Orthogonal experiments: Calculate the adsorption capacity and adsorption rate of adsorbent by the measured concentration of heavy metals in wastewater containing zinc, the data was shown in Table-1.

Comparison of the importance of factors: As can be seen, the conclusion that the relationship between the range of absorption rate and adsorption capacity is the same, the order is $\mathrm{C}>\mathrm{D}>\mathrm{A}>\mathrm{B}$, it shows the $\mathrm{pH}$ has the maximum impact on the adsorption rate. In order to obtain intuitive response to the various factors on the adsorption capacity and adsorption rate, make the diagram of adsorption capacity and factors and the adsorption rate.Among the effects on adsorption capacity, the effect of the concentration of small ball is the smallest and therefore graphics fluctuations are minimal, the range of $\mathrm{pH}$ levels is the higher and then its graphic fluctuations is the largest, its effect on adsorption capacity and adsorption rate is also the largest. The effects of adsorption rate and adsorption capacity are consistent.

Analysis of variance: The analysis of variance of adsorption rate was shown in Table-2. In Table-2, we choose the factor $\mathrm{F}_{\mathrm{a}}$ which with smallest deviation as control factors; factor $\mathrm{C}$ has the highly significant effect on adsorption capacity, Table3 showed that the priority of factors pointer and the best program were: The priority of all factors is $\mathrm{C}>\mathrm{D}>\mathrm{A}>\mathrm{B}$ and the optimal program is $\mathrm{C} 4 \mathrm{D} 3 \mathrm{~A} 1 \mathrm{~B} 3$. That is, under the condition that $\mathrm{pH} 7.0$, oscillation $110 \mathrm{~min}, 37^{\circ} \mathrm{C}$, the concentration of small ball is $1.1 \mathrm{~g} / \mathrm{L}$ the adsorption effect is the best.

In Table-3, factor B has a highly significant on adsorption capacity, from Table-3 we can see that the priority of factors pointer and the best program were: The priority of all factors is $\mathrm{C}>\mathrm{D}>\mathrm{A}>\mathrm{B}$ and the optimal program is C4D3A1B3. That is, under the condition that $\mathrm{pH} 5.5$, oscillation $20 \mathrm{~min}$, $37^{\circ} \mathrm{C}$, small ball is $1.1 \mathrm{~g} / \mathrm{L}$.

\section{Experimental conditions}

Relationship between time and adsorption capacity: Oscillation Leptospirillum ferrooxidans immobilized alginate adsorption capacity for zinc is higher than the adsorption amount of standing and the oscillation time to reach adsorption equilibrium is longer than standing time. This is because after the oscillation, the contact surface of sodium alginate immobilized Leptospirillum ferrooxidans and heavy metal ions is greater, leading to more ions adsorption. In addition, the concentration of dissolved oxygen in water increase with oscillation and it is also conducive to bacteria adsorb heavy metal ions better, so the oscillating adsorption capacity is higher than standing adsorption capacity and the time of reaching equilibrium when oscillating time is longer.

Effect of $\mathbf{p H}$ on the adsorption performance: The optimum $\mathrm{pH}$ were in the vicinity of 7, with the $\mathrm{pH}$ value decreases, the adsorption capacity also showed a downward trend, which is due to under strong acidic conditions, the concentration of $\mathrm{H}^{+}$was large, combined with the negative charge of bacterial surface, led to the negative charge to the adsorbent surface reduce, thereby to reduce the adsorption capacity of heavy metal ions, so the adsorption capacity is also small.

Adsorbent dosage's effect on the adsorption performance: With the increase of adsorbent dosage, the adsorption rate increased, while the adsorption capacity decreased. This is because the increase of adsorbent dosage leads to the amount of heavy metal ions adsorption material increase.

Influence of temperature on the adsorption properties: The optimum temperature of adsorption ions is around $37^{\circ} \mathrm{C}$, then the adsorption capacity and the adsorption rate is the highest. This is mainly due to adsorption is an endothermic process, at a certain temperature range, the higher the temperature, the 


\begin{tabular}{|c|c|c|c|c|c|c|c|c|c|c|}
\hline \multicolumn{11}{|c|}{$\begin{array}{l}\text { TABLE-1 } \\
\text { ORTHOGONAL EXPERIMENTS OF Leptospirillum ferrooxidans } \\
\text { IMMOBILIZED SODIUM ALGINATE BEADS ADSORB ZINC ION }\end{array}$} \\
\hline Test No. & A & B & $\mathrm{C}$ & $\mathrm{D}$ & \multicolumn{3}{|c|}{ Adsorption rate $(\%)$} & \multicolumn{3}{|c|}{ Adsorption capacity (mg/L) } \\
\hline 1 & 37 & 0.9 & 4 & 90 & 58.78 & 58.79 & 57.98 & 5.44 & 5.76 & 5.55 \\
\hline 2 & 37 & 1.0 & 5 & 100 & 65.28 & 67.58 & 67.48 & 6.98 & 6.56 & 6.14 \\
\hline 3 & 37 & 1.1 & 6 & 110 & 74.34 & 74.19 & 74.04 & 8.02 & 8.17 & 8.32 \\
\hline 4 & 37 & 1.2 & 7 & 120 & 76.57 & 76.60 & 76.64 & 8.85 & 8.87 & 8.89 \\
\hline 5 & 30 & 0.9 & 5 & 110 & 66.85 & 66.84 & 66.83 & 6.74 & 6.86 & 6.99 \\
\hline 6 & 30 & 1.0 & 4 & 120 & 54.64 & 54.65 & 54.67 & 4.21 & 4.33 & 4.45 \\
\hline 7 & 30 & 1.1 & 7 & 90 & 75.28 & 75.14 & 75.01 & 8.33 & 8.56 & 8.79 \\
\hline 8 & 30 & 1.2 & 6 & 100 & 72.36 & 72.24 & 72.12 & 7.21 & 7.74 & 8.27 \\
\hline 9 & 25 & 0.9 & 6 & 120 & 72.79 & 72.70 & 72.61 & 8.57 & 8.03 & 7.49 \\
\hline 10 & 25 & 1.0 & 7 & 110 & 64.48 & 64.43 & 64.38 & 6.12 & 6.16 & 6.20 \\
\hline 11 & 25 & 1.1 & 4 & 100 & 52.78 & 52.75 & 52.72 & 3.57 & 3.54 & 3.51 \\
\hline 12 & 25 & 1.2 & 5 & 90 & 64.46 & 64.41 & 64.36 & 6.64 & 6.68 & 6.74 \\
\hline 13 & 20 & 0.9 & 7 & 110 & 65.32 & 65.38 & 65.44 & 6.52 & 6.59 & 6.66 \\
\hline 14 & 20 & 1.0 & 6 & 90 & 74.72 & 74.67 & 74.64 & 8.43 & 8.31 & 8.19 \\
\hline 15 & 20 & 1.1 & 5 & 120 & 61.58 & 61.48 & 61.38 & 5.72 & 5.77 & 5.83 \\
\hline 16 & 20 & 1.2 & 4 & 100 & 49.68 & 49.78 & 49.86 & 3.19 & 3.21 & 3.15 \\
\hline Adsorption rate I & 274.77 & 262.56 & 212.81 & 259.98 & Adsorpti & pacity I & 28.36 & 26.24 & 15.34 & 28.31 \\
\hline II & 267.87 & 258.11 & 258.11 & 240.07 & & & 27.49 & 25.36 & 25.87 & 21.01 \\
\hline III & 251.29 & 260.07 & 290.80 & 289.81 & & & 24.41 & 26.04 & 32.25 & 27.78 \\
\hline IV & 249.33 & 261.54 & 280.55 & 252.75 & & & 23.83 & 26.45 & 30.18 & 27.02 \\
\hline $\mathrm{I} / 4$ & 67.94 & 65.14 & 52.78 & 64.41 & & & 7.07 & 6.56 & 3.83 & 7.07 \\
\hline $\mathrm{II} / 4$ & 66.97 & 64.53 & 64.53 & 60.02 & & & 6.87 & 6.35 & 6.47 & 5.28 \\
\hline III/4 & 62.82 & 65.02 & 72.70 & 72.45 & & & 6.10 & 6.51 & 8.06 & 6.95 \\
\hline IV/4 & 62.33 & 65.39 & 70.14 & 64.17 & & & 5.97 & 6.59 & 7.55 & 6.75 \\
\hline Range & 4.64 & 0.86 & 19.92 & 12.41 & & & 1.10 & 0.25 & 4.23 & 1.79 \\
\hline
\end{tabular}

\begin{tabular}{ccccccc}
\multicolumn{7}{c}{ TABLE-2 } \\
\hline Source of variation & Sum of squares & Freedom degree & MSE & F value & $\mathrm{F}_{\mathrm{a}}$ & Remarkable level \\
\hline A & 11.24 & 3 & 3.74 & 2.53 & & Not remarkable \\
B & 7.57 & 3 & 2.52 & 1.71 & F $0.05(3,32)=2.29$ & Remarkable evidently \\
C & 82.99 & 3 & 27.66 & 18.56 & F $0.01(3,32)=4.46$ & Rery remarkable \\
D & 19.59 & 3 & 6.53 & 4.38 & & - \\
Repeated errors e & 47.91 & 32 & 1.49 & & & \\
\hline
\end{tabular}

\begin{tabular}{ccccccc}
\multicolumn{7}{c}{ TABLE-3 } \\
\hline Source of variation & Sum of squares & Freedom degree & MSE & F value & $\mathrm{F}_{\mathrm{a}}$ & Remarkable level \\
\hline A & 3.89 & 3 & 1.29 & 3.17 & & Not remarkable \\
B & 2.23 & 3 & 0.74 & 1.79 & F 0.05 $(3,32)=2.28$ & Remarkable evidently \\
C & 22.11 & 3 & 7.35 & 17.96 & F $0.01(3,32)=4.47$ & Very remarkable \\
D & 5.27 & 3 & 1.75 & 4.28 & & - \\
Repeated errors e 2 & 13.29 & 32 & 0.41 & & & - \\
\hline
\end{tabular}

more favorable adsorption carried out and $37^{\circ} \mathrm{C}$ is the optimal growth temperature of bacteria, the activity of bacteria at this time was strong, growth was the most vigorous, so the adsorption efficiency is the highest.

Influence of shaking speed on the adsorption performance: The adsorption efficiency is the highest at the shaking speed of $150 \mathrm{r} / \mathrm{min}$ and the adsorption capacity is also the highest, this is mainly because that at the roll velocity, the concentration of dissolved oxygen in water can help alginate immobilized leptospirillum ferrooxidans adsorb heavy metal ions and the bacteria are the most active at this time, the speed is too high or too low is not conducive for alginate immobilized bacteria to adsorb heavy metal ions, so the adsorption efficiency and adsorption capacity under the condition of 150 rpm.
Control experiment: Sodium alginate as absorbent can directly adsorbed heavy metal ions, which is due to alginate molecules containing a large number of free carboxyl groups can react with metal ions, at the process of adsorption, heavy metal ions and the $\mathrm{Na}^{+}$in sodium alginate happen to exchange ions, therefore sodium alginate has the capacity of adsorbing metal ions. When the concentration of sodium alginate is $2 \%$, the embedding of the fungi had the highest growth rate and remain grow at a longer time, so the adsorption efficiency of the bacteria is higher than the non-alginate. It has the lowest adsorption rate when sodium alginate as a separate adsorbent.

Effect of temperature on the adsorption of zinc water: The adsorption rates is the highest at the optimal temperature and the adsorption can happen at room temperature, but the adsorption rate is below the optimum temperature adsorption 
rate. This is due to the adsorption reaction is an endothermic process, to a certain temperature range, the higher the temperature, the more favorable adsorption carried out and $37^{\circ} \mathrm{C}$ is the optimal temperature for growth of bacteria, bacterial activity is the highest at the temperature, and the growth is the most vigorous, so it has the maximum adsorption efficiency.

\section{Study of the mechanism of microorganisms adsorbing} heavy metals

SEM and EDS: Fig. 1 showed that the sodium alginate immobilized Leptospirillum ferrooxidans have no capsule and with flagella around, its spores oval and located in the central cell, the colonies show irregular and often form wrinkles, making the surface rough transparent. In addition, we can clearly see from the figure that the surface had obvious holes, which may be the reason for its ideal adsorption efficiency of heavy metals. Obviously, the surface of alginate immobilized Leptospirillum ferrooxidans are adsorbed a layer of silver white, a slightly blue crystalline material. From the energy spectrum of Fig. 2 can further determine the successful absorption of $\mathrm{Zn}^{2+}$.
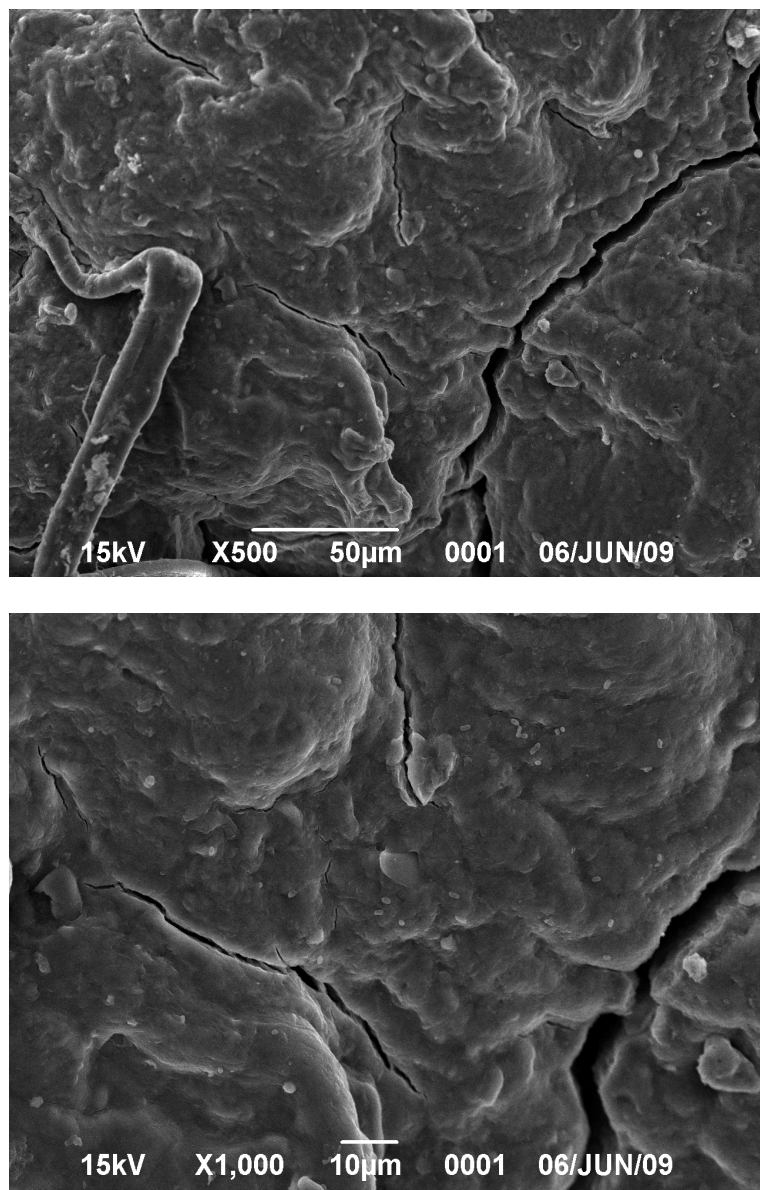

Fig. 1. Electron microscope of sodium alginate immobilized Leptospirillum ferrooxidans adsorbing $\mathrm{Zn}^{2+}$

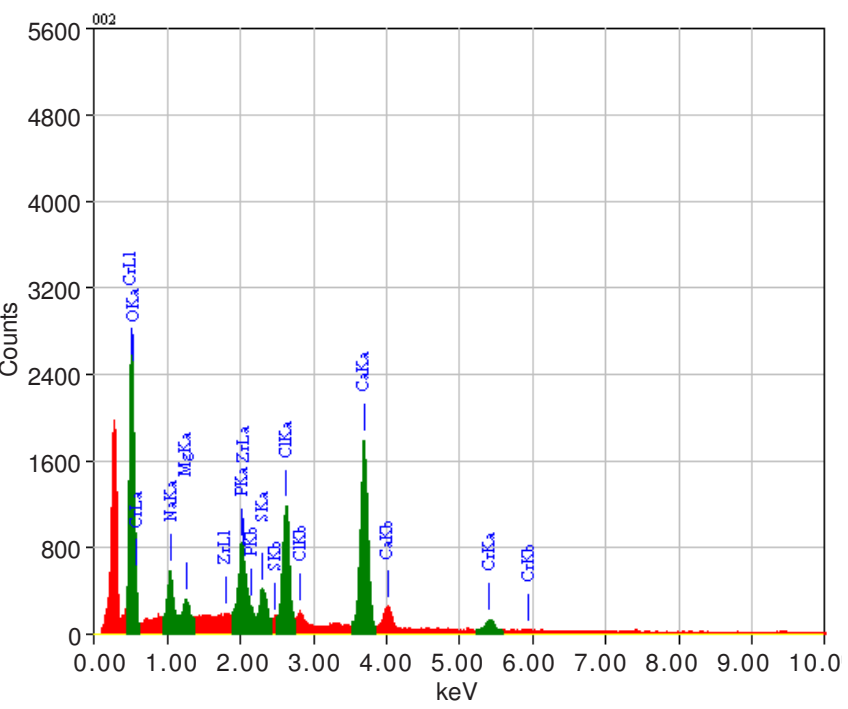

Fig. 2. Energy spectra of sodium alginate immobilized adsorbing $\mathrm{Zn}^{2+}$

\section{Conclusion}

We discussed the adsorption condition of sodium alginate immobilized Leptospirillum ferrooxidans under different time, temperature, $\mathrm{pH}$, adsorbent dosage and shaking velocity. In order to determine its further feasibility, we also discussed control experiment and adsorb experiment, reach the conclusion that: among the four factors-time,temperature, $\mathrm{pH}$ value and concentration, the influence of $\mathrm{pH}$ value on the adsorption of heavy metals in solution is most prominent and then comes the time and temperature, the small ball concentration has the smallest effect. We can obtain that sodium alginate immobilized Leptospirillum ferrooxidans have the highest adsorption rate of heavy metals, the Leptospirillum ferrooxidans have lower adsorption rate and the sodium alginate has the lowest adsorption rate through control experiment.after adsorption treatment of containing zinc mine wastewater, the concentration of zinc ions reaches the first class of irrigation water quality standards.

\section{REFERENCES}

1. M.A. Hanjra, J. Blackwell, G. Carr, F.H. Zhang and T.M. Jackson, Int. J. Hyg. Environ. Health, 215, 255 (2012).

2. A.Y. Dursun, Biochem. Eng. J., 28, 30 (2006).

3. C. Gakwisiri, N. Raut, A. Al-Saadi, S. Al-Aisri and A.Al-Ajmi, A Critical Review of Removal of Zinc from Wastewater, Proceedings of the World Congress on Engineering, Vol. 1 (2012); ISBN: 978-988-19251-3-8.

4. B. Tanse, Recent Patents on Chem. Eng., 1, 17 (2008).

5. A. Santos, P. Barton, E. Cartmell, F. Coulon, R.S. Crane, P. Hillis, J.N. Lester, T. Stephenson and S.J. Judd, Environ. Technol., 31, 725 (2010).

6. B,R. Mohapatra, W.D. Gould, O. Dinardo and D.W. Koren, Miner. Eng., 24, 709 (2011). 